\title{
Los hermanos Verdugo Landi y el arte de los periódicos
}

\author{
Inocente Soto Calzado \\ Universidad de Málaga \\ inocentesoto@uma.es
}

RESUMEN: Ricardo Verdugo Landi (1871-1930) y Francisco Verdugo Landi (1874-1954) nacieron en Málaga en una familia de periodistas, y una de sus ocupaciones artísticas fue la de ilustradores y caricaturistas en esa misma prensa, logrando el éxito a finales del siglo XIX, labor oculta tras sus conquistas en la pintura de género y en la fundación y dirección de las cabeceras más sobresalientes de la prensa gráfica e ilustrada en la España de comienzos del siglo XX. Este es un breve recorrido por la biografía de sus primeros años utilizando fuentes documentales primarias (las propias revistas de época), donde se puede constatar la importancia de su labor y su relevancia a nivel nacional.

PALABRAS CLAVE: Ricardo Verdugo Landi; Francisco Verdugo Landi; Revistas ilustradas; llustración contemporánea; Arte en Málaga.

\section{The Verdugo Landi Brothers and Newspaper Art}

ABSTRACT: Ricardo Verdugo Landi (1871-1930) and Francisco Verdugo Landi (1874-1954) were born in Malaga in a family of journalists, and worked as successful illustrators and cartoonists in the local Malaga press at the end of the nineteenth century. This work was overshadowed by their success as gender painters and by the creation and direction of the most outstanding graphic and illustrated press in Spain in the early twentieth century.

KEYWORDS: Ricardo Verdugo Landi; Francisco Verdugo Landi; Illustrated Magazines; XIX ${ }^{\text {th }}-X^{\text {th }}$ Century Illustration; Art in Málaga.

Recibido: 30 de marzo de 2017 / Aceptado: 23 de junio de 2017.

Sin duda, son admirables los logros empresariales de Francisco Verdugo Landi, y es fácil encontrar su nombre en cualquier estudio solvente sobre el periodismo español (López de Zuazo, 1981: 643), como editor de Nuevo Mundo o como fundador de Mundo Gráfico junto con Mariano Zavala, José Campúa y Tomás García Lara, o como responsable, junto con su hermano mayor Ricardo, de La Esfera (1914-1931), la revista ilustrada de corte modernista ensalzada por Benito Pérez Galdós como culmen gráfico de la edición española. Gracias a esa misma prensa puede descubrirse la auténtica importancia artística de los hermanos Verdugo Landi. La fuente documental primigenia para conocer a un artista gráfico no puede ser otra que el propio medio donde desarrolló sus cualidades, y en esos papeles caducos por su propia periodicidad, reemplazados semana a semana por una nueva entrega, pueden hallarse los testimonios de los compañeros en aquellos menesteres, de cuyas palabras puede rescatarse el pasado y narrarlo con cierto orden. Gracias a ello se puede conocer la verdadera importancia de los hermanos Verdugo Landi en el arte gráfico español de finales del siglo XIX, con una anterioridad de décadas respecto a lo apuntado hasta el momento, pues las reseñas suelen ignorar la etapa malagueña de los hermanos y sus éxitos en los grandes centros editoriales del país antes del cambio de siglo.

El escritor Manuel Carretero, asiduo de las galeradas de diferentes publicaciones, era elocuente en su discurso a comienzos del nuevo siglo: «Los Verdugo han hecho bien: yo los aplaudo. Si no se venden cuadros hay que hacer pequeños dibujos de actualidad para las Revistas; confeccionar planas, componer fotografías, la letra de una imprenta, jtodo!, antes que perecer en la contienda» (Carretero, 1905: 711). La batalla cruenta de la que habló el cronista era sin duda la del arte,

Cómo citar este artículo: SOTO CALZADO, Inocente, «Los hermanos Verdugo Landi y el arte de los periódicos", Boletín de Arte-UMA, n. ${ }^{\circ} 38$, Departamento de Historia del Arte, Universidad de Málaga, 2017, pp. 161-170, ISSN: 0211-8483, DOI: http://dx.doi.org/10.24310/BoLArte.2017.v0i38.3288 
perdida de antemano en un país que no apreciaba el talento de sus hijos y que menos aún lo sufragaba, decaído económica y moralmente tras los desastres coloniales.

El colega periodista habla de una familia dedicada al oficio, comenzando por el cabeza de una familia prolija, Joaquín María Verdugo Delgado, director de la Revista de Málaga en 1874 y La Justicia en 1888, pero sobre todo fundador, propietario y director del diario malagueño Las Noticias desde 1876, periódico donde su hijo Francisco -posteriormente famoso periodista- ejerció como crítico taurino bajo el pseudónimo de Verduguillo. Las Noticias era un periódico político republicano que llegó a ser suspendido judicialmente en 1878 y sustituido temporalmente por el título El Fénix, que también fue suspendido y vuelto a reemplazar, en este caso por El Nuevo Fénix. Las Noticias era más que un diario de actualidad, y publicaba almanaques literarios ilustrados, una edición dominical bajo el título La Capa del Estudiante que procuraba enriquecer a su manera la vida cultural de la ciudad (Díaz de Escovar, 2000: 104-115). En esa empresa familiar Francisco y Ricardo aprendieron a amar el oficio y todo lo relacionado con él, confeccionando el periódico, dibujando y escribiendo para él, nutriendo sus inquietudes, asistiendo cuando se podía a las clases artísticas, cambiando el papel por el lienzo cuando el trabajo lo permitía. Los últimos números conocidos del diario se fechan en 1897. Consagrado el padre toda su vida al periodismo en su ciudad natal, dificultades económicas y el hartazgo de la realidad política decidieron el fin de la cabecera y el traslado a Madrid de la familia.

Ricardo, el hermano mayor, había iniciado una carrera pictórica a temprana edad. Sobre 1886, a los quince años, se le sitúa en el aula de Emilio Ocón, ya catedrático de la Escuela de Artes y Oficios de Málaga, figura señera de la segunda generación de la escuela pictórica malagueña, auténtico valedor del tema marinista dentro de la pintura malagueña. En la ciudad comienzan a circular, al año siguiente de sus primeras enseñanzas pictóricas, las producciones de Ricardo, pequeñas tablas de estilo minucioso y temática ingenua (Cuenca, 1923: 380).

Un poco más tarde habría que situar una de las primeras obras de Francisco en su ciudad natal, según declaraciones del propio autor al poeta José Francisco Sanmartín, un semanario para niños titulado La Pelota, un proyecto que demuestra la precocidad de su genio al fundarlo con quince años, y prueba el alcance de sus cualidades al mantenerlo durante cerca de dos años, aunque solo, parece ser, con aportaciones literarias (Sanmartín, 1901: s.p.). La publicación se encuentra recogida en la temprana hemerografía de la prensa malagueña, donde se cita su periodicidad semanal, su creación en 1889 como periódico para niños y se presenta como director a Francisco García Verdugo (Díaz de Escovar, 2000: 152). Francisco fue además alumno de la Academia de Bellas Artes de Málaga, dedicado y laborioso, premiado por ello; al tiempo cursaba el Bachillerato, para realizar una carrera de leyes a la postre inconclusa por problemas económicos.

Mientras Ricardo pintaba, Francisco comenzó a realizar caricaturas en el ámbito familiar, entre las que el propio artista recuerda la dedicada a su padre. A pesar del declarado amor por el periodismo, el hermano menor siempre tuvo clara la fuerza de su otra pasión en esos primeros años como creador, y así hacía memoria ante uno de sus colegas entrevistador: «Aunque acaso mi afición más destacada era la del dibujo» (Carretero, 1944: 460). Es el momento histórico en el que las revistas ilustradas de gran formato denominadas ilustraciones, dirigidas a un público culto pero diverso y basadas en un principio en reproducciones xilográficas a contrafibra, van cediendo su lugar a revistas de menor formato donde predomina el fotograbado tras los inicios litográficos. Se intenta llegar a un lector mayoritario a menor precio y con nuevos intereses, consolidándose el género joco-serio (Bozal, 1979: 191-198).

La revista Málaga Alegre fue el desarrollo lógico de esa primigenia dedicación gráfica y de la naturalidad con la que los hermanos habían crecido en el mundo de la edición. Era un «periódico semanal festivo, literario, ilustrado», como anunciaba su subtítulo, realizado por Francisco junto a su hermano Ricardo, aparecido el 7 de junio de 1891 y del cual se conservan tres números provenientes de la colección de Narciso Díaz de Escovar ${ }^{1}$. Con sede en la calle Mariblanca, 17, la revista se publicaba los domingos; cada uno de los números se componía de ocho páginas, y la parte gráfica era mayoritariamente humorística, con un dibujo caricaturesco al servicio del chiste fácil. En la parte literaria llama la atención la contundencia de las firmas, donde es fácil encontrar a autores locales de calidad como Arturo Reyes y a otros nacionales de gran prestigio y recorrido en el momento, como Luis Taboada o José Jackson Veyán. Los textos se impri- 
mían en la tipografía de Las Noticias, diario al fin y al cabo familiar. Según declaraciones a Sanmartín, Francisco era el dibujante único, dejando su trabajo sin firmar por modestia, lo cual no parece corresponder en todo con la realidad: desde el primer número, la cabecera está dibujada por Verdugo, pero hay trabajos firmados con una grafía distinta [1], encontrándose también la firma R. Verdugo. Eso sí, varios sin firma, de carácter narrativo, demuestran un dominio considerable de las figuras y de su expresividad y movimientos. Se encuentran también en otras páginas firmas como Busquets y E. Jaraba, esta última en una preciosa portada que parece corresponder por estilo al pintor malagueño Enrique Jaraba, autor que posteriormente volvería a colaborar con los hermanos Verdugo en La Esfera, con algunas portadas e ilustraciones interiores en varios números.

Concentrado en el mundo de la pintura, en 1892 Ricardo ya había donado al Museo Municipal de la ciudad su obra Pidiendo auxilio, donde se enfrenta al tema de la marina con exceso de arrojo, sumándole al género la variante del asunto dramático de la barca a merced del oleaje. Prueba de su inclusión en el mundo pictórico local es que será quien suceda a José Ruiz Blasco (1838-1913), el padre de Picasso, en el cargo de conservador del Museo Municipal de Málaga. En ese año se presenta a la Exposición Internacional de Bellas Artes de Madrid, coincidente con el IV Centenario del Descubrimiento de América, firmando como alumno de Ocón y de Joaquín Martínez de la Vega, almeriense asentado en Málaga y gran figura de la pintura local malagueña. Obtiene mención honorífica con Desembarcando, y en la Exposición Regional en el Liceo de Málaga obtiene medalla de plata. No abandona la labor editorial, pues en 1895 aparece como director de Málaga Cómica², revista homónima de la editada diez años antes por Ramón Urbano, pero la simultanea con su desarrollo como pintor, concursando en la Exposición Nacional de 1895 con su cuadro Naufragio, sin premio a pesar de unas imponentes dimensiones al estilo oficial (Sauret, 1987: 757). En general, los títulos de sus producciones muestran bien a las claras la dedicación marítima del pintor.

Tras estas primeras experiencias algunos de los hermanos Verdugo se marchan a Orán, en Argelia, que bajo la administración francesa se convirtió en sitio de peregrinaje de colonos europeos, muchos de ellos españoles, que implantaron su modelo cultural sobre la población entrante, como prueban las palabras de Guy de Maupassant que



1. Verdugo Landi, Francisco y Ricardo, Málaga Alegre, año I, n. ${ }^{0}$ 1, 7/6/1891, portada. Archivo Díaz de Escovar. Fundación Unicaja. Málaga

hablaban de Orán como una ciudad verdaderamente más española que francesa (cit. en Belaskri, 2016); allí trabaja Francisco como redactor-jefe del diario El Noticiero, en el cual escribe bajo la firma Paco la sección en verso Casos y cosas. Proyecto fracasado, del cual comentaba el protagonista que casi tuvieron que volver a nado.

La vuelta a Málaga será por breve tiempo, y el año 1897, con los últimos números conservados de Las Noticias y la renuncia de Ricardo al Museo Municipal se convertirá en uno de los últimos en la ciudad del sol. La familia se instalará en Madrid, donde las oportunidades artísticas serán en teoría mayores para los dos hermanos, tras, eso sí, arduo 
trabajo. Las ilusiones pictóricas de Ricardo chocaron con la realidad de la falta de clientela, teniendo que dedicarse a pintar cuadros expresamente para ser subastados en las salas de puja que estaban de moda en la época, formando un pequeño taller con Francisco, que preparaba los lienzos y pintaba cielo y mar, hasta que las telas recibían los retoques de Ricardo, que terminaba finalizando embarcaciones y figuras (Carretero, 1944: 461). Es posible que incluso Francisco no desdeñara del todo en un principio continuar también él una carrera pictórica, pues en los escuetos apuntes sobre los pintores malagueños editados en 1908, a cargo del polifacético pintor, dibujante, fotógrafo, sobrino y gobernador civil Antonio Cánovas del Castillo y Vallejo, también conocido como Kaulak, solo hay una frase bajo su nombre: «Figura presentando un Estudio en Madrid á la Exposición de 1899» (Cánovas, 1908: 70).

En Madrid Francisco dará continuidad sobre todo a una fructífera carrera como dibujante de revistas ilustradas, encontrándose su obra reproducida con asiduidad a partir de ese momento, pero no solo en la ciudad de acogida, sino que en paralelo publicará también en el otro gran centro editorial del momento, Barcelona. Y no estará solo, sino que se verá normalmente acompañado por su hermano Ricardo, cada uno con un estilo bien definido: ilustrador figurativo Ricardo, caricaturista Francisco. Por lo tanto, no solo Francisco Verdugo Landi formaba parte a finales del siglo XIX de los nombres más pujantes del arte gráfico español, como se encargaba de dar cuenta una breve nota biográfica: «Dibujante y caricaturista muy acreditado por su fino humorismo y punzante sátira» (Cuenca, 1923: 379); también Ricardo fue una figura capaz de copar las portadas de muchas de las revistas ilustradas de éxito, mucho antes de su paso por la empresa de Torcuato Luca de Tena y su trabajo en $A B C$ y Blanco y Negro, y con más de quince años de antelación a su éxito rotundo junto con su hermano en una publicación tan emblemática en el arte español como La Esfera, loada por Baltasar Peña Hinojosa, con la opinión de que una parte de la popularidad de la obra marinista de Ricardo se debía a la difusión que se hacía de ella en sus páginas (1971: s.p.).

Francisco figura como escritor, junto a Ramón Urbano, en un Almanaque gráfico repartido por distintas publicaciones castellanas al comienzo de 1898 (La Campana Gorda, de Toledo, La clave, de Salamanca y Diario de Soria), pero el apellido Verdugo Landi aparece desde mayo de 1898 con asiduidad en revistas de la capital como Madrid Cómico, Nuevo Mundo, La Revista Moderna, La Vida Literaria, La Ilustración Española y Americana o La Lectura Dominical. A la conocida carrera madrileña en prensa de los dos hermanos hay que sumar su presencia en revistas barcelonesas como El Gato Negro, La Saeta, Frégoli, Iris o Vida Galante, con trabajos constatados antes de la finalización del siglo. Así decía un breve anuncio de una revista catalana: "Los celebrados dibujantes de la Corte, hermanos Verdugo Landi, tan conocidos por sus geniales dibujos, empezarán a honrarnos con sus trabajos desde el próximo número»³. Málaga ya los había perdido como artistas, pero ellos empezaban a encontrar la fama, o por lo menos una cierta consideración en otras ciudades.

En cuanto a fechas, Madrid Cómico puede ser uno de los primeros lugares, si no el primero, en publicar el trabajo gráfico de Francisco. La famosa revista humorística de la capital nació en 1880 como periódico semanal festivo e ilustrado, desapareciendo en 1923 con la dictadura de Primo de Rivera. Una vida larga y llena de éxitos, con una difusión en 1897 de casi ocho mil ejemplares semanales (González, 2005: 675). Existía un solo artista en Madrid Cómico, y ese era Ramón Cilla Pérez (1859-1937), que firmaba en la práctica todos los grabados aparecidos durante el año, excepción hecha de alguna contada intervención ajena. Con Bernardo Rodríguez Serra como propietario a final de 1897 y Luis Ruiz de Velasco como director la revista se abrirá a los nuevos autores, incorporando a los malagueños Francisco Sancha Lengo y Francisco Verdugo Landi. Sancha publicó en el mes de abril en Madrid Cómico, La Revista Moderna y Blanco y Negro, dando inicio a una de las más brillantes carreras gráficas de final de siglo (Soto, 2014: 58), y Verdugo lo hará dos meses más tarde, primero en Madrid Cómico y después en Nuevo Mundo, empezando a hablarse de las dos jóvenes promesas del humorismo hispano. El estilo de los dos partía de la realidad para deformarla y mostrar expresivamente su sustancia, centrando su vis cómica en el estudio de sus personajes, en su forma más adecuada, y Verdugo mostraba un especial talento para las fisonomías. Cada una de sus entregas iba subiendo en calidad, y en pocos meses el dibujo de Francisco mostraba una factura profesional de máximo nivel [2]. Llegarán a la revista los jóvenes barceloneses Joaquín Xaudaró, Baldomero Gili Roig, Isidre Nonell, Lluis Bonnín, Joaquín Mir, Joaquín Torres García y Xavier Gosé, y 


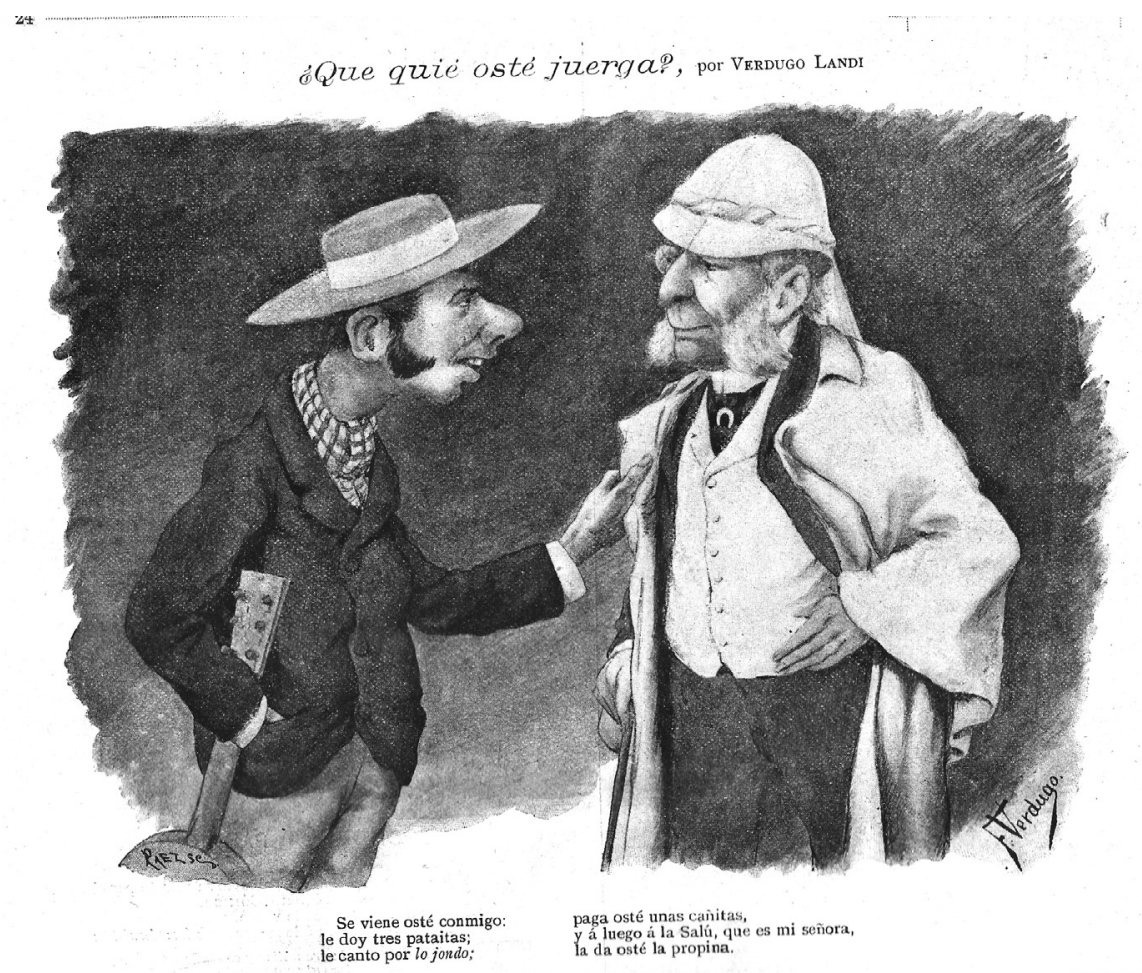

2. Verdugo Landi, Francisco, Madrid Cómico, año XIX, n. ${ }^{\circ}$ 3, 21/10/1899, p. 24. Col. BASL,

esa amplia nómina, competencia de ilustradores de gran calidad, hará que posiblemente Ricardo aparezca en la editorial más tarde que Francisco, en otra cabecera. El 7 de enero de 1899 nacerá la revista La Vida Literaria, con Bernardo Rodríguez de administrador propietario y Jacinto Benavente de director. Las relaciones están claras con Madrid Cómico, pues éste se regala con La Vida Literaria cada quincena, y en él aparece Ricardo con alguna ilustración de tema costumbrista, poco habitual y no relacionado hasta el momento con su producción gráfica.

Nuevo Mundo será el semanal más relacionado con los hermanos, pues el propio Francisco, tras comenzar la colaboración gráfica en él, llegará posteriormente a la dirección del mismo a propuesta del propietario, José del Perojo, que lo había fundado en 1894. Sin embargo, será Ricardo quien más publique en sus páginas en un principio, a raíz fundamentalmente de sus capacidades como ilustrador realista. El hecho de que en el mes de abril de 1898 la tensión hispano-norteamericana estallara y la guerra de independencia cubana pasara a ser la guerra con Estados
Unidos servirá para que Ricardo muestre sus dotes en la plasmación de las escenas marinas o terrestres relacionadas con el conflicto, ya sea sobre el buque o en la frondosa manigua, continuo homenaje a unos soldados siempre en franca inferioridad frente al poderoso enemigo, una realidad que aplastaba cualquier fantasía del sentimiento patriótico. Su intuición periodística junto a sus capacidades con el pincel le valdrá publicar a finales de mayo tanto en La Revista Moderna como en Nuevo Mundo, junto a dibujantes especialistas como Antonio de Caula o Rafael Monleón, que eran hasta el momento los encargados, además de la fotografía, de dar cobertura gráfica al conflicto, dados sus conocimientos técnicos, pues uno era ingeniero y el otro piloto naval (Casado Cimiano, 2006). Desde la entrada de la escuadra española en Santiago de Cuba, la visita a los marinos del Ministro del ramo, el bombardeo de Puerto Rico, la importancia de las palomas mensajeras, el bloqueo de la bahía o el último combate, el pincel de Ricardo dejará constancia del enorme esfuerzo español por salvar ante la nación algo del honor mancillado, y así lo expresó en una de sus más curio- 


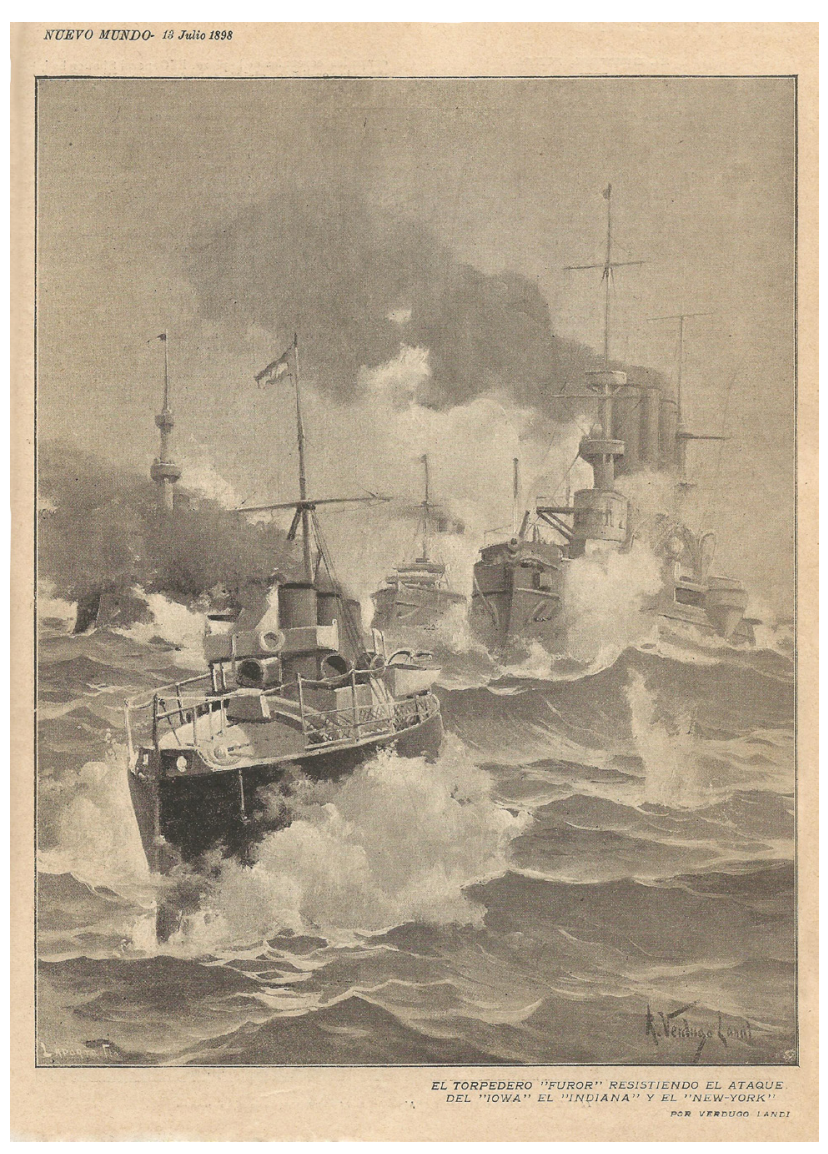

3. Verdugo Landi, Ricardo, Nuevo Mundo, año V, n. ${ }^{0}$ 236, 13/7/1898, s.p. Col. BASL, Málaga

sas ilustraciones, donde los barcos parecen humanizarse y la pequeña nave española atacada por las impresionantes máquinas de guerra enemigas se convierte en la personificación del militar español frente al ejército estadounidense [3]. En comparación con la labor de Ricardo, Francisco publicará en este año pocos dibujos, sin gran importancia ni tamaño en la página, concentradas en la imagen caricaturesca y prototípica del yanki, si bien es cierto que a partir de octubre su trabajo será de mayor calidad y se irá adueñando de la composición de la página, con alguna contraportada a color antes del final del año.

Respecto a la pintura, en 1899 volverá Ricardo a conseguir una mención honorífica en la Exposición Nacional de Madrid con Oleaje, viviendo uno de sus mejores momentos artísticos, dedicándole su atención la conocida revista barcelonesa La llustración Artística, que publica su dibujo La pesca del bou en aguas de Málaga al tiempo que loaba su juventud y la capacidad demostrada en el cuadro triunfante en la Exposición Nacional ${ }^{4}$.

En Barcelona, la carrera de los hermanos será muy importante. Al calor de la actualidad y al mismo tiempo que lo publicado por Nuevo Mundo aparecerá en el semanal barcelonés El Gato Negro alguna ilustración sobre la realidad militar en Cuba, traducción plástica de las noticias, con la pintura luchando en inmediatez con la pujante labor de la fotografía, y Francisco también dejará constancia en la misma revista de su maestría en el dibujo humorístico. El ejemplo más interesante de la labor gráfica de los hermanos en Barcelona se publicará a partir de 1899, en Iris, una de las revistas barcelonesas más sorprendentes del fin de siglo, luciendo novedades estéticas propias del modernismo y la presencia continuada del apellido Verdugo Landi. Allí Francisco tendrá mucho más espacio para su labor, siendo un colaborador fijo al que se le dedica página y color, dejando constancia de su buen hacer en la creación de tipos y en el retrato profundo de los personajes siempre con una mirada amable [4]. Ricardo había aparecido en la prestigiosa revista Álbum Salón ${ }^{5}$, con la ilustración Obra de caridad, a color y a plena página, cuidada reproducción que a pesar del título volvía a mostrar un tema marinero; en Iris será el autor de un buen número de portadas e ilustraciones interiores, no solo con su reconocida labor de pintor del mar, sino también peleando con las más diversas temáticas al uso, desde la salida de misa, la vendedora del mercado o la visión idílica del mundo rural, siempre aportando una especial sensibilidad cromática, por encima de su dominio de las formas [5]. Su selección en el Certamen Artístico de Blanco y Negro en el comienzo del siglo, junto a otros artistas malagueños o relacionados con la escuela pictórica de la ciudad como César Álvarez Dumont, Pedro Sáenz o Rafael Murillo Carreras ${ }^{6}$ refrendará su calidad y su posición en el mundo artístico.

Durante algunos años más, Francisco seguirá publicando ocasionalmente dibujos, pero sus labores en la dirección de periódicos y su peso cada vez mayor en la empresa Prensa Gráfica le irán restando tiempo. Uno de sus últimos y más completos trabajos aparecerá en Alma Española, publicación símbolo del regeneracionismo y cuna de muchos de los escritores adscritos posteriormente a la denominada generación del 98. La revista nació en noviembre de 1903 para terminar en abril de 1904, sin completar un año de existencia 


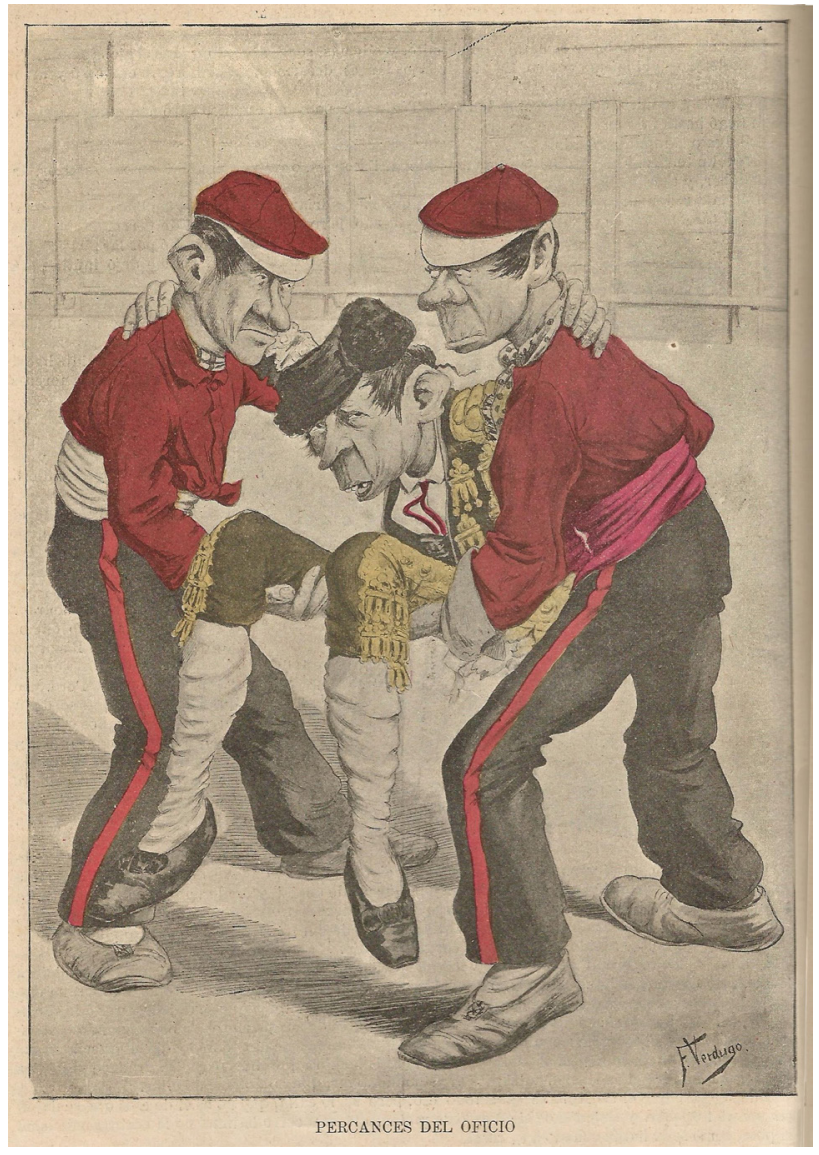

4. Verdugo Landi, Francisco, Iris, año II, n. ${ }^{\circ} 49$, 14/4/1900, s.p. Col. BASL, Málaga

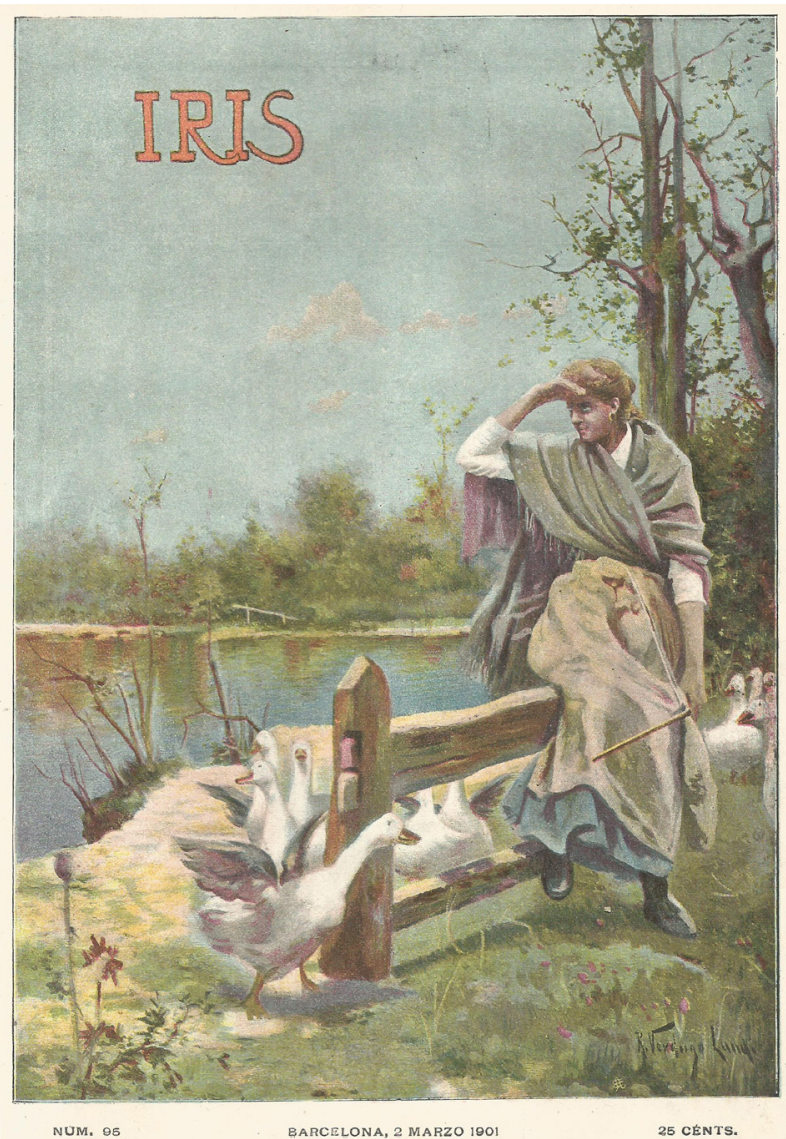

5. Verdugo Landi, Ricardo, Iris, año III, n. ${ }^{\circ}$ 95, 2/3/1901, portada. Col. BASL, Málaga con sus 23 números. A pesar de su corta historia, su edición pasa por varios períodos, donde se destacan José Martínez Ruiz, Azorín, Ramiro de Maeztu y Pío Baroja (O’Riordan, 1978: VIII). Se pueden encontrar en esas páginas dibujos de Francisco en 1904, junto a los de humoristas consagrados como Karikato, Sileno y nuevos valores como el malagueño Tomás Sancha Lengo, siguiendo las directrices anticlericales y políticas de la revista, con especial virulencia hacia el partido conservador y las figuras del presidente del Consejo de Ministros Antonio Maura y de Raimundo Fernández Villaverde y su labor económica, como se puede observar en una contundente y crítica portada donde el dibujo queda al servicio de la política [6].

José Francés, en su faceta de crítico de arte y en una conferencia pronunciada en el Ateneo de Madrid, trazaba ya en 1915 un curioso panorama sobre la caricatura española contemporánea, repasando con nostalgia lo que había quedado de ese arte tan pujante en los últimos años del siglo, entre el inmovilismo, las pérdidas tras la batalla y la huida a la búsqueda de una comida al día: «Francisco Verdugo abandonó por completo los lápices de caricaturista, y primero en Nuevo Mundo y luego en Mundo Gráfico y por último en La Esfera, esta revista orgullo de España, ha dado nuevo rumbo más admirable a su espíritu de artista» (Francés, 1915: 34).

Ricardo, por el contrario, nunca abandonó la ilustración, siendo mucho más conocida su labor al discurrir el nuevo siglo (Prados, 1934: 56). En la prensa periódica comenzó especialmente a partir de 1907 a colaborar con Blanco y Negro, destacando con alguna espléndida portada a todo color; su polivalencia acompañó las aventuras 


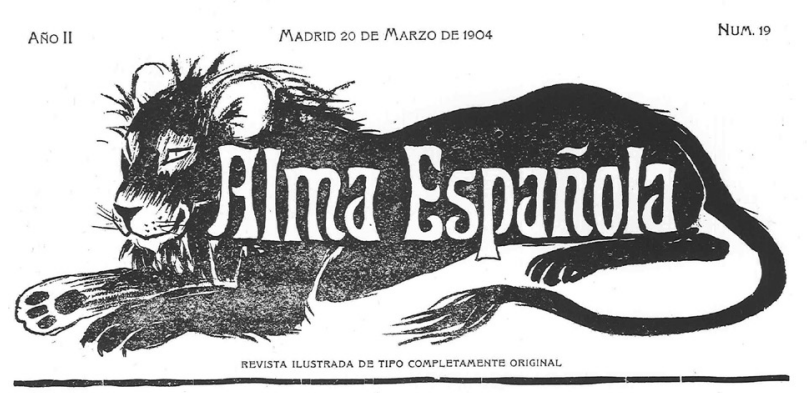

"RIDICULUS MUS", por F. Verdugo.

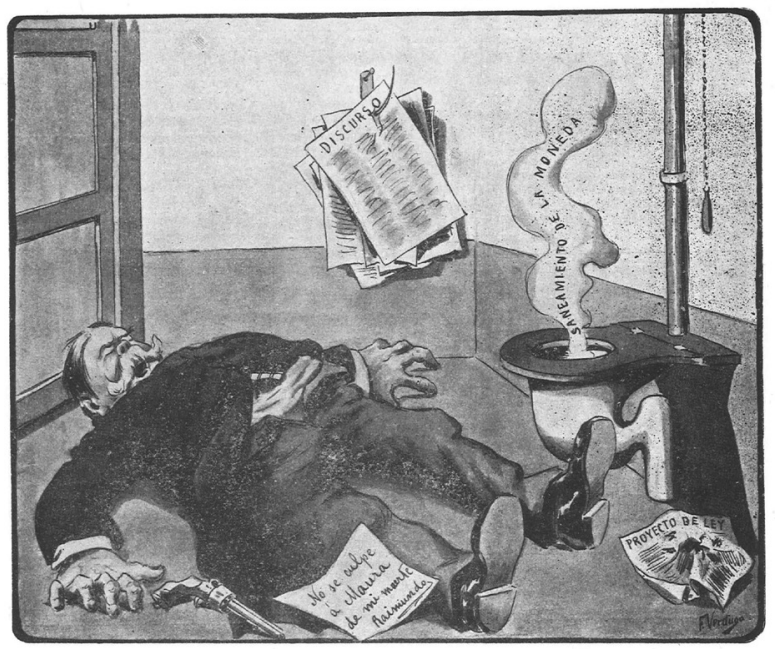

DiEZ Y SEIS páqinas: DIEZ céntimos.

6. Verdugo Landi, Francisco, Alma Española, año II, n. ${ }^{0}$ 19, 20/3/1904, portada. Facsímil Col. BASL, Málaga

periodísticas de su hermano Francisco, como lo prueba su trabajo continuado en La Esfera desde 1914 a 1930 (Sánchez Vigil, 2003: 311-313). Sus imágenes para monografías literarias lo consolidaron como un ilustrador hábil y versátil; Francisco ya había ilustrado en 1905 los cuentos de Floresta Cómica ${ }^{8}$, y Ricardo amplió su labor en el campo de la ilustración con las destinadas a las ediciones de libros, en trabajos colectivos como el de Yelmo Florido en 1918, con un solo pero magnífico dibujo de línea del oleaje golpeando unas rocas, o en solitario para diversos números de La No-

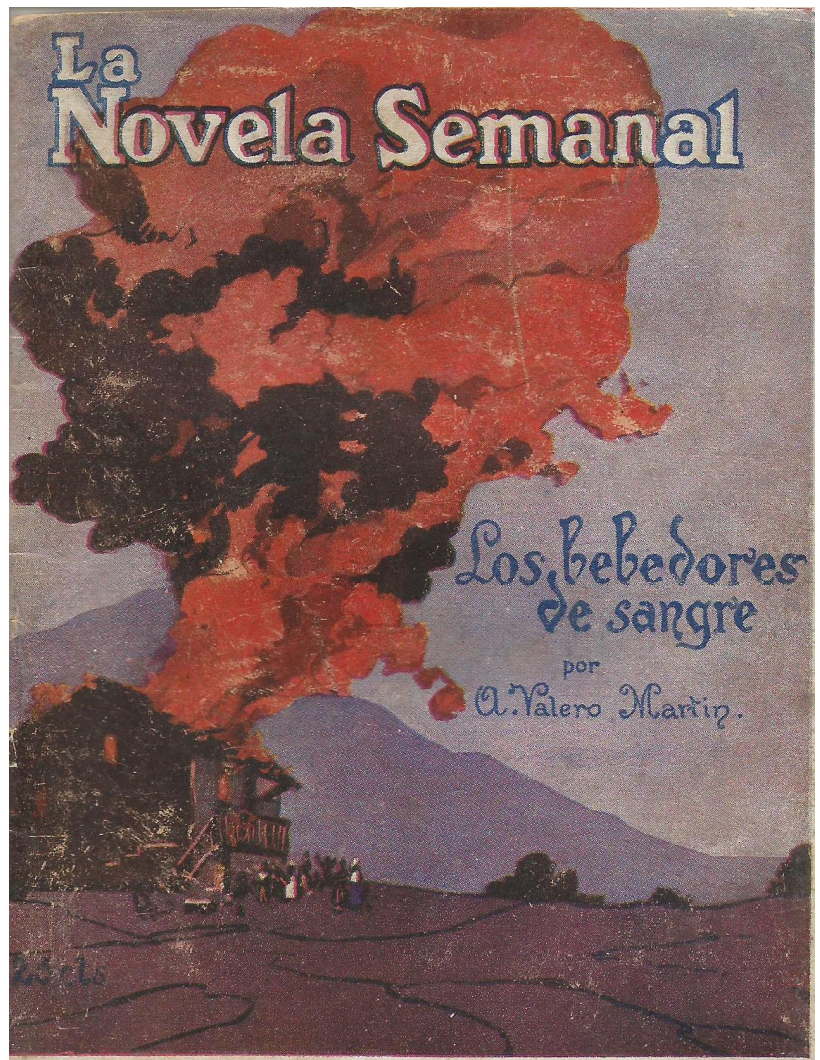

7. Verdugo Landi, Ricardo, Los bebedores de sangre, por A. Valero Martín, col. La Novela Semanal, año III, n. ${ }^{\circ}$ 128, 22/12/1923, Publicaciones Prensa Gráfica, Madrid. Col. BASL, Málaga

vela Semanal en 1923, como El mártir, El extranjero, No era él o Los bebedores de sangre [7].

La labor gráfica de los hermanos Ricardo y Francisco Verdugo Landi forma parte de ese patrimonio olvidado de la escuela malagueña de artistas de fin de siglo, de una historia gráfica aún no escrita que permitió divulgar el arte malagueño a nivel nacional y que se difundió desde los proyectos editoriales madrileños y barceloneses, una riqueza cultural que las crónicas han olvidado hasta el momento y que su ciudad y la historia del arte español deben procurar conocer y rescatar. 


\section{Notas}

1 http://www.museoartespopulares.com/archivo/ (fecha de consulta: 10-07-2017).

2 http://opac.malaga.eu/cgi-bin//abwebp/X5103/ID1717713395/G0 (fecha de consulta: 10-07-2017).

3 Anónimo, Frégoli, n. ${ }^{\circ} 2,13 / 10 / 1898$, p. 33.

4 Anónimo, La llustración Artística, n. ${ }^{\circ}$ 921, 21/8/1899, p. 552.

5 Álbum Salón, n. ${ }^{\circ} 37,1 / 3 / 1899$, p. 94.

6 Anónimo, Blanco y Negro, n. ${ }^{\circ}$ 462, 10/3/1900, p. 22.

7 VERDUGO LANDI, Ricardo, «La vuelta de la pesca», Blanco y Negro, n. ${ }^{\circ} 849$, 10/8/1907. Portada.

8 Editorial Noticiero-Guía de Madrid, Colección Alegría, n. ${ }^{\mathrm{X}}$.

\section{Bibliografía}

BELASKRI, Yahia, «Oran l'espagnole: l'héritage oublié». En http://simon.sirour.free.fr/page26/page26.html (fecha de consulta: 03-03-2016). BOZAL, Valeriano (1976), La ilustración gráfica del XIX en España, Alberto Corazón editor, Madrid.

CANOVAS, A. (1908), Apuntes para un diccionario de pintores malagueños del siglo XIX, edición del autor, Madrid.

CARRETERO, Manuel (1905), "La caricatura en España. Tovar. Verdugo. Xaudaró», La llustración Artística, año XXIV, n. 1244, 30/10, pp. 710-711.

CARRETERO NOVILLO, José María, «El Caballero Audaz (1944)», Galería, t. II, Ediciones E.C.A., Madrid.

CASADO CIMIANO, Pedro (2006), Diccionario biográfico de ilustradores españoles del siglo XIX, Ollero y Ramos, Madrid.

CUENCA, Francisco (1923), Museo de pintores y escultores andaluces contemporáneos, Imprenta y Papelería de Rambla, Bouza y Ca, La Habana. Ed. facsímil: (1996), Museo de pintores y escultores andaluces contemporáneos, Obra Socio Cultural Unicaja, Málaga.

DÍAZ DE ESCOVAR, Narciso (2000), Bibliografía de la prensa malagueña. Apuntes para la historia del periodismo en la provincia de Málaga, El Corte Inglés, Málaga.

FRANCÉS, José (1915), La caricatura española contemporánea, Sociedad General Española de Imprenta, diarios, revistas y publicaciones, Madrid.

GONZÁLEZ FREIRE, José Manuel (2005), «Medio siglo en Madrid. Memorias de un escritor público de tercera fila», Anales del Instituto de Estudios Madrileños, XLV, CSIC, pp. 673-699.

LÓPEZ DE ZUAZO ALGAR, Antonio (1981), Catálogo de periodistas españoles del siglo XX, Fundación Universidad-Empresa, Madrid. O’RIORDAN, Patricia (1978), «Prólogo», en Alma Española, Edición facsímil, Turner, Madrid, pp. VII-XIV.

PEÑA HINOJOSA, Baltasar (1971), Ricardo Verdugo Landi, Caja de Ahorros Provincial de Málaga, Málaga.

PRADOS Y LÓPEZ, Manuel (1934), Pintores malagueños contemporáneos, Academia Provincial de Bellas Artes de San Telmo, Málaga. SÁNCHEZ VIGIL, Juan Miguel (2003), La Esfera. Ilustración Mundial (1914-1931), Libris, Madrid.

SANMARTÍN Y AGUIRRE, José Francisco (1901), «Perfiles cómicos. Francisco Verdugo», Iris, n. 121, 31/8/1901, s/p.

SAURET GUERRERO, Teresa (1987), El siglo XIX en la pintura malagueña, Universidad de Málaga, Málaga.

SOTO CALZADO, Inocente (2014), Dibujantes con París al fondo. Picasso y las revistas ilustradas, Fundación Picasso Museo Casa Natal, Málaga. 
